\title{
Implicações da utilização do conceito de risco para a prática em APS
}

\section{Implications of risk conception \\ for the basic care pratice}

Michele Lopes Pedrosa ${ }^{1}$

Carlos Eduardo Aguilera Campos ${ }^{2}$

\begin{abstract}
"Desde Galileu, Descartes e Newton, nossa cultura tem estado tão obcecada com o conhecimento racional, a objetividade e a quantificação, que nos mostramos muito inseguros ao lidar com os valores e a experiência humana."
\end{abstract}

(Fritjof Capra)

\section{RESUMO}

A produção do conhecimento e as ações de saúde têm relação direta com as bases conceituais e metodológicas dadas pela Epidemiologia. Três temas relevantes do conceito de risco são problematizados neste texto: as construções de inferências coletivas a partir da apreciação de agregados; a necessidade de redução da complexidade dos fenômenos estudados e seu isolamento de influências externas; o descarte da subjetividade na construção dos modelos que prezam pela objetividade, linearidade e rigidez. As implicações deste pensamento científico são analisadas em suas potencialidades e, especialmente, em suas limitações para a prática clínica na Atenção Primária em Saúde.

\section{ABSTRACT}

Production of knowledge as well as health actions are directly related to the conceptual and methodological bases provided by Epidemiology. This paper discusses three relevant themes of risk conception: the construction of collective inferences based on the judgment of values; the need of reducing the complexity of the studied phenomena and isolating them from external influences; avoidance of subjectivity in the construction of models excelling in objectivity, linearity and precision. The implications of this scientific thinking are analyzed in their potentialities and especially in their limitations for the clinical practice in Primary Health Care.

PALAVRAS-CHAVE:

- Epidemiologia;

- Atenção Primária a Saúde.
KEY-WORDS:

- Epidemioly;

- Primary Health Care.

${ }_{1}^{1}$ Doutoranda em Epidemiologia, Médica, Instituto de Ginecologia, Universidade Federal do Rio de Janeiro, Rio de Janeiro, Brasil.

2 Doutor em Medicina Preventiva, Professor Adjunto, Programa de Atenção Primária à Saúde, Faculdade de Medicina, UFRJ, Rio de Janeiro, Brasil. 


\section{Introdução}

A Epidemiologia tem como questão central a determinação da freqüência e distribuição de eventos relacionados à saúde das populações e suas causas, com o objetivo de propor intervenções que concorram para o controle das desordens de saúde. O objeto da Epidemiologia, portanto, é a doença enquanto um fenômeno coletivo. Atualmente, sua maior contribuição para as ciências da saúde constitui-se em estudar as relações entre agravos e seus determinantes, sendo o fator de interesse estudado em uma população de referência por meio de métodos estatísticos responsáveis pela mensuração das associações utilizadas para a construção de uma relação causal' ${ }^{1}$.

A evolução da Epidemiologia refletiu a evolução das ciências da saúde e o conhecimento a respeito das teorias causais e dos fatores envolvidos na gênese das doenças na população. Dentre os momentos marcantes, podem ser citados: a teoria miasmática, dominante até as descobertas pasteurianas; a distribuição das doenças em populações distintas, segundo as classes sociais da Inglaterra, no final do século XIX; os modos de transmissão das doenças infecciosas, que surgiu com o progresso da bacteriologia no final do século XIX; o modelo ecológico sobre o equilíbrio entre agente, hospedeiro e meio ambiente; a associação entre doenças e os fatores de risco de diversas naturezas, modelo hegemônico nos nossos dias, que se tornou o modelo analítico das doenças crônico-degenerativas ${ }^{2}$. De acordo com esses marcos referenciais, foram sendo desenvolvidas investigações científicas fundamentadas nos respectivos modelos teóricos subjacentes, visando à obtenção de explicações para a gênese e o comportamento das doenças e ao desenvolvimento de formas de enfrentamento das mesmas ${ }^{3}$.

Em Epidemiologia é fundamental a relação causal, que busca identificar a relação temporal entre os fenômenos em estudo, possibilitando intervenções que mudem o curso natural dos mesmos. A identificação, pela bacteriologia, de agentes patogênicos específicos responsáveis pela ocorrência de doenças infecciosas fortaleceu a prioridade em estudos causais. Após a Segunda Guerra Mundial, entretanto, o crescimento das doenças crônico-degenerativas não-transmissíveis, nas quais os modelos de determinação unicausal não se aplicavam, fez com que se incorporasse o conceito de risco segundo o estudo de probabilidades ${ }^{4}$.

Fator de risco pode ser definido como característica ou circunstância determinável de uma pessoa ou de um grupo de pessoas associada a um risco anormal de aparecimento, ou evolução, de processo patológico ou de afeç̧ão especialmente desfavorável 5 . Com base no modelo de risco epidemiológico, os sistemas de saúde dedicamse ao controle dos agravos à saúde, combatendo os fatores de risco a eles associados e oferecendo subsídios para o enfrentamento das doenças crônico-degenerativas. Mais recentemente, essas estratégias foram definidas como de prevenção primária e secundária, tal como preconiza o modelo da História Natural da Doença ${ }^{6}$.

Como base filosófica hegemônica a Epidemiologia teve uma forte influência da concepção positivista de ciência, segundo a qual esta deve manter-se neutra, livre de juízos de valor. Nessa visão, os fatos são situações objetivas, totalmente 
inteligíveis, suficientes à ciência. O pensamento empírico também compõe esse referencial filosófico, só sendo passível de tratamento científico o que for mensurável, resultando no desenvolvimento de métodos de investigação fundamentados em análises matemáticas, quantitativas ${ }^{7}$.

O método indutivo de Francis Bacon, no qual as leis e teorias eram derivadas da observação, dominou o pensamento científico e epistemológico até, pelo menos, as primeiras décadas de 1900. Este método tinha como base a observação por distintos pesquisadores de séries de casos ou experiências semelhantes, que são registradas sistematicamente, possibilitando a definição de leis naturais e teorias, as quais se ajustam aos fatos conhecidos e explicam o modo como estes ocorrem $^{8}$. Neste paradigma, a imprevisibilidade e o acaso são somente decorrências do desconhecimento humano sobre determinados fatos naturais ${ }^{9}$.

Critérios de demarcação entre o científico e o não-científico foram definidos por Popper, o qual afirmou que os procedimentos de investigação deveriam ser racionais, devendo ser afastados fatores subjetivos, psicológicos ou estéticos, que não desempenhariam papel algum na formação e avaliação das teorias científicas, as quais seriam guiadas exclusivamente por critérios lógicos bem definidos ${ }^{8}$.

A ciência objetiva, empírica e positiva considerou que a única fonte consistente de conhecimento científico deve estar fundamentada na idéia da objetividade, estabelecendo que o conhecimento somente é aceitável quando segue a lógica da quantificação, desconsiderando as características qualitativas presentes na prática cotidiana e legitimando o poder do conhecimento formal e instru- mental, por estabelecer a crença inabalável na neutralidade da investigação científica, na inexistência da influência da subjetividade. Estava, então, estabelecida a dicotomia entre sujeito e objeto ${ }^{10}$.

A racionalidade absoluta na geração do conhecimento, porém, foi criticada por diversos pensadores, que consideram a ciência como um empreendimento anárquico, conferindo-Ihe um caráter mais humanitário, com maior capacidade de estimular o progresso do que a rigidez racionalista ${ }^{8}$.

Desde a formulação das teorias da relatividade e quântica, a física buscou um novo referencial epistemológico para lidar com as dúvidas e as incertezas das novas situações que surgiram na apreciação de seus objetos de estudo. Raciocinando sob o prisma da teoria dos sistemas complexos, os produtos dos processos retroagem sobre os próprios processos, modificando suas características, propriedades e seus atributos. O pensamento complexo traz uma nova concepção, da existência de desordens e incertezas na organização do mundo e dos seres viventes, que funcionam como um conglomerado caótico, auto-regulável e auto-organizado ${ }^{11}$.

A presença de objetos híbridos, constituídos por aspectos naturais e culturais, que se dispõe em redes que são influenciadas por vetores naturais, sociais e discursivos, torna difícil a tarefa de compreensão dos mesmos por meio das disciplinas institucionalizadas ${ }^{12}$. Não é possível explicar, pela lógica, as inter-relações entre o todo e suas partes. Indivíduo, sociedade e espécie são termos que se finalizam um no outro, remetem-se um para o outro, em um circuito que é um verdadeiro sistema, isto é, onde as partes integram o todo de maneira a manter sua interdependência ${ }^{13}$. 
Conclui-se, portanto, que a contribuição da "Epidemiologia dos fatores de risco" é a de identificar determinadas relações entre causa e efeito, mesmo que não se consiga atingir um completo entendimento da contribuição de cada um deles na causa de um determinado fenômeno. Esse esquema referencial, ainda que tenha os seus limites, serve de guia mestre para a prática assistencial. Nos dias de hoje, a Medicina passa a propor modelos de prevenção, de modo a reduzir ou controlar a ocorrência dos fatores de risco a elas associados.

Predizer a possibilidade de ocorrência de eventos futuros, que assim se tornam passíveis de controle, envolvendo a teoria da probabilidade, e a sofisticação da estatística e das ciências computacionais é a principal contribuição do conceito de risco epidemiológico. O seu cálculo consiste na estimativa da força de correlação estatística na determinação dos efeitos relacionados ao fator analisado, estimando sua probabilidade e magnitude. É, portanto, fundamentalmente quantitativo ${ }^{14}$. A contagem dos eventos possibilita alguma previsibilidade na ocorrência dos mesmos, sobretudo nas áreas das ciências humanas e biológicas, permitindo cálculos probabilísticos, partindo da análise de um conjunto de dados para definir teorias e leis que permitiam a predição, excedendo a observação que lhes originou ${ }^{9}$.

O avanço das técnicas estatísticas e computacionais, além da sofisticação dos métodos epidemiológicos, possibilitou a monitoração e o desenvolvimento de estratégias de controle de riscos em saúde. O estudo de efeitos deletérios ou protetores de determinados fatores informa profissionais de saúde e indivíduos em sua prática cotidiana. A identificação e a redução de riscos constituem objetivos centrais da Saúde Pública na atualidade, sendo a experimentação o critério básico de rigor e legitimidade científica utilizado na construção dos métodos de avaliação de riscos ${ }^{15}$.

\section{A aplicação do conceito de risco}

Em Epidemiologia, o vocábulo risco se refere à probabilidade de que um evento (morte ou adoecimento) venha a ocorrer dentro de um determinado período, sendo os fatores de risco marcadores de predição da morbi-mortalidade futura $^{16}$. A mensuração do risco pelo cálculo da incidência e a comparação dos riscos entre indivíduos expostos e não-expostos a determinado fator são procedimentos indispensáveis à identificação dos fatores de risco e, portanto, da rede da causalidade dos eventos adversos à saúde. Há, basicamente, três formas de quantificação de risco: o risco absoluto, que se refere à razão entre o número de eventos ocorridos sobre o total de eventos que poderiam ter ocorrido; o risco relativo que se refere à razão entre o risco de ocorrência do evento em uma população exposta a um determinado fator e o risco de ocorrência deste mesmo evento em uma população não exposta ao fator; o risco atribuível, que é a fração do risco a que está exposto um grupo da população e que é atribuível, exclusivamente, ao fator estudado.

$\mathrm{Na}$ estimativa quantitativa do risco, podese apontar questões de caráter metodológico e epistemológico: 1) as construções de inferências coletivas a partir da apreciação de agregados; 2) a necessidade de redução da complexidade dos fenômenos estudados e seu isolamento de influências externas; 3) o descarte da participação 
da subjetividade na construção dos modelos que prezam pela objetividade, linearidade e rigidez.

Quanto à primeira questão, pode-se afirmar que, no discurso epidemiológico, risco se refere a populações, situando-o para além do sujeito individual, sendo sua inferência legítima como fenômeno de caráter coletivo. Por não ser possível a observação simultânea do efeito da exposição e da não-exposição a determinado fator em um mesmo indivíduo, utilizam-se grupos populacionais, pressupondo a distribuição aleatória da heterogeneidade individual nas amostras selecionadas. Valores médios referentes aos agregados são analisados e calculados, extrapolando-se estes achaachados para o nível individual, o que pode acarretar problemas quanto à validade das inferências. Isso porque a aleatoriedade para a eleição dos indivíduos em grupos de comparação, com objetivo de evitar erros na análise epidemiológica, não permite inferir a probabilidade individual de cada sujeito se expor a um determinado evento, de maneira independente da exposição em estudo. Dessa forma, os indivíduos não seriam igualmente informativos, podendo contribuir para subestimação ou sobre-estimação de risco ${ }^{16}$.

Procede-se, portanto, um deslocamento da lógica coletiva para a lógica individual, cuja aplicabilidade prática é questionável haja vista que o risco agregado somente pode corresponder ao risco individual se os sujeitos apreciados são homogêneos, pressuposto não considerado pela própria epidemiologia. Essa limitação é de fundamental importância no entendimento sobre a aplicação desses conhecimentos, quer se lide com indivíduos, quer com comunidades. ${ }^{17}$ Essas questões são estudadas na Epidemiologia e na Sociologia, sob a rubrica das falácias ecológicas e significa dizer: o que é válido para o nível agregado pode não o ser para o nível do indivíduo ou vice-versa ${ }^{4}$.

A Clínica moderna tem utilizado esses conhecimentos sobre risco em sua prática, em transposições de inferência coletiva para a individual de forma, muitas vezes, arriscada. Visa assim diminuir, à força, incertezas relativas aos processos decisórios. Pretende-se, dessa forma, eliminar as incertezas que se originam da subjetividade do exercício clínico, em busca de se constituir uma prática pretensamente técnica, imparcial e neutra. O risco singular atribuído ao indivíduo, então, que surge no discurso clínico, decorre do risco epidemiológico, transpondo-se inferências com base na observação de populações para indivíduos constituintes ou não dessas populações, pressupondo-se que os membros individuais manifestariam a média dos atributos de uma dada população ${ }^{18}$.

Quanto à segunda questão aqui levantada, pode-se afirmar que o pensamento probabilístico embasou a crença no gerenciamento dos riscos, com a ruptura da passividade diante do futuro. Porém, para que a determinação da probabilidade de ocorrência futura de eventos seja calculada, pressupõe-se a manutenção dos mesmos padrões de relação entre os fatores de risco e o desfecho de interesse, ou seja, é indispensável uma dada regularidade. Não podem ocorrer variações, temporais ou espaciais, do objeto, no que diz respeito às suas características e propriedades, nem na sua inter-relação com o meio exterior ${ }^{19}$. Em outras palavras, é essencial uma estabilidade das condições de ocorrência do fenômeno para que o sujeito investigador o apreenda com fidedignidade: o objeto de estudo não pode variar em suas carac- 
terísticas, seus atributos, suas propriedades nem em suas inter-relações espaço-temporais com o meio circundante.

O ideal em um estudo epidemiológico é que todos os fatores distintos das exposições e desfechos de interesse possam ser isolados, criando condições ideais de observação da relação causaefeito. Dessa maneira, o fenômeno considerado passa a ser estudado a partir da construção de uma realidade fictícia, simplificada, desconsiderando aspectos importantes do mesmo. O reducionismo utilizado para viabilizar as operações estatísticas interfere no entendimento e enfrentamento dos fenômenos em questão, na medida em que fragmenta o indivíduo indivisível, reconstruindo o todo como uma mera soma das partes, e o isola de seu meio externo, indispensável para sua existência, e com o qual mantém inter-relações contínuas e dinâmicas ${ }^{15}$.

A determinação de fatores de risco apóiase na utilização de recursos estatísticos e tecnológicos, em desenvolvimento crescente nas últimas décadas. Para que essa análise ocorra, é necessário separar da realidade complexa e mutável cadeias de causalidade independentes, constituídas de múltiplos co-fatores, que interagem por meio de relações lineares. ${ }^{20} \mathrm{~A}$ estimativa do risco, por meio de técnicas lineares, na abordagem de fenômenos humanos complexos, dotados de interação entre componentes biológicos, psicológicos e sociais, vem mostrando-se insuficiente. A constatação desse fato levou ao desenvolvimento de métodos não-lineares de modelagem matemática dos sistemas dinâmicos ${ }^{21}$.

$\mathrm{Na}$ análise de determinados eventos, observa-se que noções estabelecidas sobre co- nhecidos fatores de risco apresentam instabilidade, possivelmente por abordarem fenômenos complexos interativos, constituídos por aspectos biológicos, sociais e psicológicos, por meio de técnicas lineares de estimação de risco. A teoria da nãolinearidade, ou do caos, tem sido proposta como alternativa epistemológica e metodológica para a ciência contemporânea ${ }^{22}$.

O conceito de complexidade relaciona-se à mudança, considerando a seta do tempo. Os modelos anteriores, independentes da sofisticação tecnológica apresentada, são essencialmente reducionistas, compreendendo os fenômenos pelo isolamento de sua dinâmica, convergindo para uma mesma produção fixa. A teoria da complexidade critica a delimitação de limites espaçotemporais e de precisão necessária à lógica da objetividade, introduzindo a idéia de fluidez destes limites entre os elementos de um sistema ${ }^{23}$.

A teoria dos sistemas complexos introduz conceitos de contradição, confusão e ambigüidade, não passiveis de formalização lógica, logo desconsiderados pela racionalidade científica clássica. Acrescenta-se a estes, a "borrosidade" ("fuzziness"), propriedade particular dos sistemas complexos no que se refere à natureza dos limites têmporo-espaciais impostos ao fenômeno, seja a nível infra-sistêmicos (unidades do sistema), ao próprio sistema em suas relações com outros sistemas ou com os contextos (supersistemas) nos quais se encontra inserido. ${ }^{23}$ A ciência convencional impõe delimitações precisas de tempo e espaço para os elementos de um dado sistema, quando na realidade existe fluidez ("borrosidade" / "fuzziness"). Essa lógica implica na recuperação da contextualização, por meio da noção de impre- 
cisão dos limites externos dos sistemas e das suas interfaces com os demais sistemas e com os supersistemas nos quais se inserem. A "teoria dos conjuntos borrosos" ("fuzzy set theory"), por Lofti Zadeh, é uma das concepções associadas à teoria da complexidade, que objetiva lidar com a incerteza, com a ambigüidade e com valores imprecisos e, assim, aproximar-se mais da realidade ${ }^{24}$.

A crítica à noção de limites implica, também, em questionamentos acerca da objetividade, visto que a relação do observador e do fenômeno é influenciada pelos limites da percepção individual, podendo apresentar ambigüidades e contradições ${ }^{25}$. Nesse sentido, o raciocínio humano não estaria fundamentado somente em sistemas dicotômicos ou na constatação ou não de um fato, em expressões numéricas ou estatísticas, mas também no quanto ele acredita na ocorrência de um evento, ou na influência que um acontecimento tem sobre outro.

Uma das características da lógica clássica é o axioma do "Terceiro Excluído", que afirma a nãoexistência de alternativa para um valor verdade além do par \{Verdadeiro, Falso\}. Ao lidar com problemas do mundo real, no entanto, pressupõe-se que o conhecimento disponível não seja absolutamente verdadeiro nem absolutamente falso, podendo ser, por exemplo, paradoxal, incerto, desconhecido, indeterminado, verdadeiro em geral, verdadeiro com uma certa probabilidade e assim por diante. Para estender a lógica clássica de maneira a permitir o tratamento deste tipo de conhecimento, é necessário alterar o conjunto de valores \{Verdadeiro, Falso\}. Dentre as alternativas propostas para alterar este conjunto de valores encontra-se a lógica "fuzzy". Nesta, uma premissa varia em grau de verdade de 0 a 1 , podendo ser parcialmente verdadeira ou parcialmente falsa, constituindo uma poderosa ferramenta para lidar com as verdades parciais, imprecisões e incertezas dos problemas no mundo real. De acordo com a visão tradicional, a ciência deve ter base na precisão, especificidade e certeza, enquanto a inespecificidade, a inconsistência e a incerteza são consideradas como não-científicas. Já, de acordo com a lógica "fuzzy", a incerteza é considerada essencial para a ciên$\mathrm{cia}^{26}$.

A característica especial da lógica "fuzzy", também referida como lógica nebulosa e em alguns casos como "Teoria das Possibilidades", é a de representar uma forma inovadora de manuseio de informações imprecisas, de forma muito distinta da "Teoria das Probabilidades". A lógica "fuzzy" possui um método interessante de inferir conclusões e gerar respostas fundamentadas na compreensão e tradução de expressões verbais, ações cotidianas de funcionamento racional, vagas, imprecisas e qualitativas, típicas da comunicação humana, em valores numéricos. Os conjuntos "fuzzy" embasam a geração de técnicas eficazes para a solução de problemas, com uma vasta aplicabilidade, especialmente nas áreas de controle e tomada de decisão.

Apesar da teoria da borrosidade aproximarse claramente de fenômenos da área da saúde, a utilização dessa noção na definição das exposições e desfechos e das determinações de risco apresenta-se incipiente. O uso potencial dessa abordagem nas ciências da saúde é evidente, sobretudo nas análises de graus e superposição de exposições e gravidades diferenciadas ${ }^{27}$.

No campo da Epidemiologia, diversas apli- 
cações deste modelo na análise de risco vêm resultando em experiências bem-sucedidas, tendo o estudo pioneiro sido realizado em 1985, por Schaffer \& $\mathrm{Kot}^{28}$, que identificaram, pela análise da incidência de sarampo entre 1928 e 1963, em Nova Iorque e Baltimore, fluxos caóticos, não-lineares.

A terceira e última questão, qual seja a subjetividade do conceito de risco remete à idéia de que a avaliação dos riscos não pode se restringir a um processo exclusivamente objetivo, reduzido à dimensão quantitativa, necessitando ser analisado como um construto, instituído histórica e culturalmente. A objetividade parece não dar conta de um problema tão humano quanto o da própria opção por viver "um risco", e a negação desta escolha parece querer negar a compreensão de por que determinados riscos são mais ou menos aceitáveis socialmente.

A abordagem quantitativa do risco atribuiIhe características próprias, autônomas, independentes do contexto sociocultural dos indivíduos. $\mathrm{O}$ risco é, então, dotado de substância, de concretude, materializando-se como agente invasor potencial, com "vida própria", e que, quando em contato com o indivíduo, leva ao aparecimento de agravos à saúde. A epidemiologia adotou essa conceituação, passando a lidar não com sujeitos individuais, pessoas, mas categorizando indivíduos dentro de escalas de "perfis epidemiológicos" e de "comportamentos de risco". Na prática clínica, a materialização do risco, implica na transformação da presença de um marcador de predição de um evento (fator de risco) em uma entidade clínica, considerada no mesmo conjunto de sinais e sintomas que constituem um quadro clínico. Ou seja, o perfil de risco de um indivíduo incorpora-se ao processo de identificação da doença, ganhando status de objeto nosológico, propedêutico e diagnóstico. Se é necessária a identificação de fatores de riscos nos sujeitos individuais, impõese o desenvolvimento da propedêutica dos riscos, assim como de formas de abordagem terapêutica e profilática dos mesmos ${ }^{27}$.

Assim, para as Ciências Sociais, risco pode ser mais bem entendido como um construto, instituído histórica e culturalmente ${ }^{29}$. A percepção de risco é uma construção coletiva, sendo que as escolhas individuais se fazem em base a valores inerentes ao meio familiar e social no qual o sujeito se insere. Estes desenham, a priori, cenários nos quais determinados fatores são enfocados em detrimento de outros. A partir daí, os valores subjetivos individuais se colocam, envolvendo aspectos diversos, de genéticos a éticos, muitas vezes afirmados por argumentações morais ${ }^{30}$. Muito da incompreensão sobre comportamentos de risco deriva do fato deste ser analisado de forma descontextualizada: independente do local, do momento e das condições afetivas envolvidas. Em suma, não haveria a presunção da cultura como inerente a todo processo social e a idéia de que a ocorrência da doença é resultado de fenômenos sociais que são singulares segundo o tempo e o espaço.

$\mathrm{Na}$ vida cotidiana, risco é interpretado a partir das experiências subjetivas, sociais e pessoais, como a possibilidade de ocorrência de determinado evento ou como uma ameaça à saúde e à vida. ${ }^{31}$ As percepções de risco diferem de acordo com características demográficas, econômicas, culturais, familiares, sociais, valores e interesses pessoais. Estes aspectos não podem 
ser desconsiderados ao se desenvolver ações de intervenção em saúde, seja no âmbito coletivo ou individual. As opções por determinados comportamentos ditos "de risco" são idealizadas e realizadas por sujeitos, como resultado de complexas configurações biológicas, psicológicas e socioculturais, dependentes de diversos e distintos constituintes, de genéticos a éticos.

As escolhas individuais podem ser influenciadas por interesses políticos e econômicos, dirigidas por pressões (das indústrias) dos modos de produção e consumo, social e individual, e pela ineficiência dos mecanismos de regulação e controle por parte dos Estados (organismos governamentais na proteção do meio ambiente e da sociedade). Atualmente, pode-se falar na existência de uma (indústria) cultura do risco, legitimado pela imensa produção científica a cerca desta temática, englobando de riscos ambientais a comportamento individual. ${ }^{12}$ Os discursos científicos e tecnológicos são produzidos e se incorporam, em uma dinâmica de retroalimentação, ao contexto histórico e sociocultural ao qual pertencem.

A aceitação ou negação pessoal de determinados eventos como potenciais agravos à saúde constitui comportamentos moldados em um ambiente limitado temporalmente, geograficamente e socialmente. As escolhas individuais de estilos de vida e hábitos de saúde são diretamente afetadas pela realidade histórica nas quais os sujeitos estão inseridos, seja pelo meio (ambiente) social, quanto pelo meio ambiente (físico) ${ }^{32}$. Muitas vezes, não se aplica o vocábulo escolha, ou, em outras vezes, ignora-se que o indivíduo é submetido a riscos involuntariamente, não sendo portanto sujeito de escolhas, como aquelas condições inerentes a sua condição de vida, como nos casos de exposição à poluição ambiental e às condições de moradia insalubres.

Uma vez compreendida a relatividade e a natureza subjetiva do conceito de risco, torna-se clara a influência do contexto cultural no comportamento de cada indivíduo. O que é aceito ou não como potencialmente nocivo à saúde varia de uma cultura para outra. Por isso, a analise dos comportamentos de riscos só pode ocorrer se fundamentada em pressupostos culturais, segundo a dinâmica da evolução social e cultural ${ }^{33}$.

\section{Considerações Finais}

Não é objetivo deste artigo desconsiderar as inúmeras contribuições da Epidemiologia para o controle de riscos para a saúde. Essas se materializaram em ações de notável impacto nas áreas da Clínica e da Vigilância. Buscou-se, contudo, descrever e analisar os limites da produção deste conhecimento para a compreensão do fenômeno saúde e doença e, ainda, para efetividade da atuação clínica.

Deve-se considerar, em particular, a natureza ampla e complexa dos problemas em Atenção Primária à Saúde. Estes se apresentam em grande variedade, sendo metodologicamente improvável que se possa trabalhar sistematicamente com padronizações nosológicas de natureza anátomo-patológica. Quanto ao comportamento dos indivíduos, há pouca previsibilidade: estes têm ampla liberdade de decidir quando, onde e quem deve atendê-los. Muitos outros fatores nãocontroláveis incidem fortemente neste campo: socioeconômicos, culturais, políticos. ${ }^{34}$ A prática cotidiana de "prescrever comportamentos e atitu- 
des", como receitas fechadas escritas em folhas de receituários, pode servir mais como alívio pelo dever cumprido de quem as ditou do que como uma solução para o indivíduo que retorna para a vida real e concreta.

A principal questão a ser superada está no fato de que o desenvolvimento da Epidemiologia dos fatores de risco tem contribuído para a consolidação de práticas de intervenção sanitária que privilegiam apelos a mudanças de hábitos individuais nocivos. Não há, contudo, um enfoque sobre como lidar com as escolhas de risco e suas causas mais profundas ou ainda como é gerada a situação na qual o risco se apresentou no indivíduo e na comunidade.

Por último, há ainda mais um fator limitante: múltiplos fatores "não-controlados" não são passíveis de análise e delimitação, incluindo aí a subjetividade do próprio conceito em si. Encarar essas questões é fundamental, pois nos permite questionar as estratégias dos serviços e dos profissionais de saúde em seu cotidiano assistencial. Assim, ao se lançar mão dos conhecimentos sobre os fatores de risco, deve-se ao menos estar consciente de suas possibilidades e de suas limitações.

A teoria da complexidade e a lógica "fuzzy" poderão contribuir para o entendimento do processo saúde-doença, à medida que propõem uma nova racionalidade científica. A inclusão de conceitos de imprecisão e incerteza concorre para a aproximação dos problemas teóricos à prática cotidiana. Assim, o que se espera são processos de tomada de decisão - principalmente no nível individual, base do exercício clínico diário -, mais eficazes a partir de uma nova abordagem metodológica.

Dentre as várias limitações aqui analisadas, podemos destacar que o foco preconizado e centrado no indivíduo imputa um controle sobre um número limitado de comportamentos pessoais prédefinidos, desconsiderando/ignorando/restringindo as inúmeras dimensões e os aspectos sociais e históricos particulares que os determinam. Sendo estes comportamentos contextualizados por situações variadas, o entendimento dessas influências poderia auxiliar profissionais de APS a ampliar 0 seu olhar e a sua análise a respeito das interações entre indivíduos e seus contextos em situações de risco.

Os aspectos culturais, sociais e econômicos se refletem, de forma indiscutível, nos comportamentos individuais, o que justifica um olhar mais amplo, com vistas a ações de prevenção e promoção da saúde. Poderíamos exemplificar esta atitude como "pensar fora da caixa", isto é, imaginar que outros aspectos e fatores certamente estão a incidir sobre o processo saúde-doença-saúde na realidade concreta de pessoas, famílias e comunidades. Ao realizar-se a transposição das mensurações de risco em populações sob o ambiente da investigação científica para sujeitos concretos, sofre-se o risco de desconsiderar a interação de múltiplos determinantes, fruto de entendimentos e percepções subjetivas, de escolhas que se dão no cotidiano das pessoas e famílias, fruto de valores esposados historicamente, muitas vezes insondáveis.

Não considerar a limitação das ferramentas de predição à disposição dos profissionais ou ainda a avaliação da real capacidade de intervenção torna o serviço menos potente para agir de forma efetiva.

A avaliação do risco pelas ciências da saúde continuará tendo grande importância para 
a melhoria da qualidade de vida das populações e do sujeito individual. Para que se torne ainda mais efetiva nesse sentido, faz-se necessária a discussão de aspectos epistemológicos e metodológicos associados à abordagem dos fenômenos, seja de caráter quantitativo ou qualitativo. A aceitação do fenômeno natural como um evento interativo, dinâmico, de limites imprecisos, permite uma maior aproximação da realidade, podendo contribuir de forma mais satisfatória no entendimento das relações causais, fornecendo subsídios para definição de políticas de controle de agravos e redução de danos. Entretanto, considerações subjetivas devem ser agregadas a mensurações, permitindo lidar de maneira mais eficaz com as questões relativas à melhoria da qualidade de vida, indo ao encontro das proposições dos novos paradigmas de atenção à saúde, os quais tem base nas abordagens holísticas do indivíduo integrado em seu meio ambiente físico, político, econômico e social.

A probabilidade tem servido de base a muitas decisões na atualidade, por conferirem características de objetividade e cientificidade. Se as informações provenientes dos métodos epidemiológicos convencionais e da determinação de probabilidades são importantes na orientação de decisões, particularmente no campo da Medicina, guiando opções diagnósticas e terapêuticas, nem sempre a evidência cientifica poderá revelar toda a complexidade de fatores que estão a interagir na realidade. Tem-se a apreensão de uma parte desta totalidade. Nem sempre esta dará ao profissional, como muitos defendem, um mapa das ações que serão mais apropriadas para a situação particular que se coloca.
A presunção de que toda a verdade emana das evidências científicas pode levar a soluções das mais equivocadas. É necessário que nossa capacidade de análise sobre a situação se amplie. A vivência cotidiana dos sujeitos, das famílias, da história e da cultura pode nos dar pistas importantes para ampliar a compreensão dos fenômenos de saúde e doença com os quais nos deparamos na prática do dia-a-dia.

Não estar tão confortavelmente se- guro de que nossos modelos possam alcançar os resultados que pretensamente prometem alcançar poderia ser um primeiro passo a nos estimular a curiosidade e criatividade, aguçando a nossa capacidade de buscar relações tanto gerais quanto singulares dos fenômenos que observamos, entender as origens das escolhas ou as impossibilidades das mudanças de "comportamento". Porque, certamente, há muito mais mistérios entre o céu e a terra do que pressupõe a nossa filosofia.

\section{Referências}

1. Guilam MCR. O Conceito de Risco - Sua utilização pela Epidemiologia, Engenharia e Ciências Sociais. Disponível em: http:// www.ensp.fiocruz.br/projetos/esterisco/ maryfim1.htm Acesso em: 5 ago 2004.

2. Barata RCB. A Historicidade do Conceito de Causa. In: Carvalheiro JR (Org.). Textos de Apoio: epidemiologia I. Rio de Janeiro: ABRASCO; 1990. p.13-27.

3. Susser M. Epidemiology in the United States after World War. II. The evolution of technique. Epidemiol Rev. 1985; 17:147-77.

4. Susser M. Causal Thinking in the health sciences. New York: Oxford University Press; 1973. 
5. Organização Mundial da Saúde. Manual sobre enfoque de risco na saúde materno-infantil. Brasil: OMS: 1983.

6. Gonçalves RBM. Investigação epidemiológica e prática médica. In: Costa (org.) Epidemiologia: Teoria e Objeto. São Paulo, Rio de Janeiro: HUCITEC-ABRASCO; 1994.

7. Minayo MCS. O desafio do conhecimento pesquisa qualitativa em saúde. 2. ed. São Paulo, Rio de Janeiro: HUCITEC-ABRASCO; 1993.

8. Jacobina RR. O paradigma da epistemologia histórica: a contribuição de Thomas Kuhn . História, Ciências, Saúde - Manguinhos. nov. 1999-fev. 2000; 6(3): 609-630.

9. Maciel EMGS, Telles FSP. Ensaio sobre a relação epistemológica entre probabilidade e método científico. Cad Saúde Pública. 2000; 16(2):487-497.

10. Barata RB. Epidemiologia clínica: Nova ideologia médica? Cadernos de Saúde Pública. 1996; 12: 555-560.

11. Prigogine Ilya. As leis do caos. São Paulo: Unesp; 2002.

12. Castiel LD. Vivendo entre exposições e agravos: a teoria da relatividade do risco. Disponível em: http://www.ensp.fiocruz.br/projetos/esterisco/ inicio1.htm. Acesso em: 5 ago 2004.

13. Morin E. A cabeça bem feita: repensar a reforma, reformar o pensamento. 6. ed. Rio de Janeiro : Bertrand Brasil; 2002

14. Spink MJ. Trópicos do discurso sobre risco: risco-aventura como metáforana modernidade tardia Cad Saúde Pública. 2001; 17(6):1277-1311. 15. Czeresnia D. Ciência, técnica e cultura: relações entre risco e práticas de saúde Cad Saúde Pública. $2004 ; 20(2): 447-455$.
16. Waldman EA., 1998. Vigilância em Saúde Pública. São Paulo : Faculdade de Saúde Pública da Universidade de São Paulo; 1998. v.7.

17. Greenland S. Randonmization, statistics, and causal inference. Epidemiology. 1990; 1: 421-429. 18. Czeresnia D, Albuquerque MFM. Modelos de inferência causal: análise crítica da utilização da estatística na epidemiologia. Rev Saúde Pública. 1995; 29(5): 415-23.

19. Halloran ME, Struchiner CJ. Study designs for dependent happenings. Epidemiology. 1991;2:331338.

20. Rose G. Individuos enfermos y poblaciones enfermas. In: Organización Panamericana de la Salud. El desafio de la epidemiologia. Washington, D. C.: OPAS; 1988. p. 909-9.

21. Philippe $P$, Mansi O. Nonlinearity in the epidemiology of complex health and disease processes. Theoretical Medicine. 1998; 19: 591 607.

22. Holland J. A Ordem Oculta. Lisboa: Gradiva; 1997.

23. Zadeh LA. Quantitative Fuzzy Semantics. Information Sciences. 1971; 3 .

24. Maturana H. El sentido de lo humano. Santiago de Chile (CL): Editorial Universitária; 1992.

25. Maturana H, Varela F. El Árbol del Conocimiento. 13 ed. Santiago de Chile (CL): Editorial Universitaria; 1984.

26. Nascimento LFC, Ortegab NRS. Fuzzy linguistic model for evaluating the risk of neonatal death Rev Saúde Pública. 2002; 36(6):686-92.

27. Almeida-Filho N. Anotações sobre o conceito epidemiológico de risco. Disponível em: http:// www.ensp.fiocruz.br/projetos/esterisco/ risc_epi.html Acesso em: 5 ago 2004. 
28. Schaffer WM, Kot M. Nearly one dimensional dynamics in an epidemic. J Theor Biol. 1985; 21;112(2):403-27.

29. Peters M. Education, Enterprise Culture and the Entrepreneurial Self: A Foucauldian Perspective. Journal of Educational Enquiry. 2001; 2(2): 5871.

30. Douglas M, Wildavsky A. Risk and Culture. Berkeley (US): University of California Press; 1982. 31. Beck U. La Sociedad del Riesgo. In: Las concecuencias perversas de la modernidad: modernidad, contingencia y riesgo. Barcelona: Anthropos; 1996. p. 182.

32. Ross MW, Pinto FJ. Por uma saúde pública de situações: a recontextualização do risco. Cad Saúde Pública. 2000; 16(1):59-71.

33. Capra F. O ponto de mutação. São Paulo: Cultrix; 1982.

34. Palomer R. Garantia de Calidad em atención primaria de salud. Barcelona: Doyma; 1993.

\section{Endereço para correspondência:}

Michele Pedrosa

PAPS-FM-UFRJ - Rua Laura Araujo, 36,

Cidade Nova - Rio de Janeiro, RJ

CEP: 20.211-170

Endereço eletrônico: mpedrosa@superig.com.br 